\title{
Poéticas de Macau: espaços duplos, triplos e de interculturalidade
}

Monica Simas

Universidade de São Paulo

RESUMO: ESTE BREVE ENSAIO BUSCA CARACTERIZAR ESPAÇOS DE DIFERENÇA E DE INTERCULTURALIDADE DA POESIA CONTEMPORÂNEA DE MACAU.

ABSTRACT: THIS BRIEF ESSAY TRIES TO CHARACTERIZE LOCALS OF DIFFERENCE AND OF CULTURAL INTERCHANGE ON THE CONTEMPORARY MACAO'S POETRY.

PALAVRAS-CHAVE: LITERATURA DE MACAU - INTERCULTURALIDADE - ESPAÇOS DA LUSOFONIA - MACAU - CONTEMPORANEIDADE

KEYWORDS: MACAO'S LITERATURE, CULTURAL INTERCHANGE, LUSOPHONE LOCALS, MACAO, CONTEMPORANEITY 
acau, passados 10 anos da sua transferência (1999-2009) para a República Popular Chinesa, confirma uma vocação poética de fôlego e de resistência, que se manifesta em pelo menos três línguas: português, chinês e inglês. Lugar conhecido pelo seu forte multiculturalismo, lugar tido por muitos como "de passagem" e por alguns como "de abrigo", facilmente exposto, nos meios de comunicação, por seus casinos suntuosos, por uma arquitetura pós-moderna cassinos high tech e confiante, estende-se nos fluxos da contemporaneidade, pondo nos olhos dos poetas dez mil divergências. No banquete de referências cruzadas e sobrepostas haveria mesmo um espaço dialogal que possamos chamar de "de encontro"? E, ainda, em meio a grande diversidade e diferenças culturais seria possível se falar de uma literatura de Macau, de uma poesia de Macau?

Este artigo pretende verificar algumas das condições das produções poéticas chinesa, inglesa e portuguesa bem recentes, para, a partir da leitura de poemas da poetisa Fernanda Dias, percorrer espaços de diferença e de interculturalidade. A aproximação de espaços poéticos tão complexos leva em conta que a literatura é inseparável das complexidades culturais e, sendo assim, ela é permeada por negociações de diferentes interesses políticos e sociais.

\section{Poesia chinesa de Macau - uma piscadela}

Nenhum olhar para a poesia chinesa contemporânea de Macau, neste percurso, seria possível sem as benevolentes publicações bilingües, raras, as traduções ou os textos do professor e poeta Yao Jingming, que tem mostrado às comunidades falantes da língua portuguesa boa parte do cenário literário chinês.

Em 1999, junto com Jorge Arrimar, ele organizou a Antologia de Poetas de Macau, reunindo vinte poetas de cada língua - a chinesa e a portuguesa. A edição, bilingüe, buscou a convergência das culturas que compõem o território matricialmente, já que a região tem uma história que foi atravessada, desde a chegada dos portugueses, em 1557, por autoridades governamentais portuguesas e chinesas. Um dos critérios da edição foi a residência em Macau. Os poetas não tinham que ter nascido necessariamente na região, mas tinham que ter uma permanência na terra. Segundo Yao Jingming (2007), simplesmente passar pela região ou tratar de Macau como tema não seria suficiente para que um autor pudesse ser incluído na literatura de Macau. 
A antologia foi uma iniciativa ousada, dando aos leitores de língua portuguesa e de língua chinesa a oportunidade de verem Macau através do olho outro. Ainda, como afirma Yao Jingming (2007) " [...], as culturas, embora convivam basicamente em harmonia e sem violentos conflitos, nunca conheceram uma convergência essencial e profunda". O fato de Macau ser parte de histórias distintas, ter nomeações distintas, inclusive em nomes de ruas, ser, portanto, dupla, motivou a historiadora de Hong Kong, Christina Miu Bing Cheng a defini-la como uma Jano Cultural, título do livro que corresponde à sua tese de doutorado. A imagem do mito com duas cabeças, olhando cada uma para uma direção diferente identifica o desenvolvimento paralelo e autônomo das duas culturas, chinesa e portuguesa, no mesmo espaço. Tanto a cultura portuguesa quanto a chinesa desenvolveram-se de forma própria e independente uma da outra, apesar de estarem conectadas.

No prefácio da mesma Antologia, a professora Ana Paula Laborinho afirma que, em Macau, " [...] coexistiram ao longo de anos comunidades que se conheceram mal e dialogaram pior, fechadas com poucas excepções no universo da própria língua” (p.17). Se pensarmos que, três anos antes, em 1996, a Fundação de Macau havia editado a Antologia de novos poemas de Macau, organizada pelo poeta Zheng Weiming, somente com poetas chineses e que, o mesmo acontece em 2007, quando o professor Li Guanding editou também pela Fundação de Macau a Antologia de Poesia Contemporânea de Macau, fica evidente a excepcionalidade da obra de Yao e de Arrimar. Na última antologiaschinesa, de Li Guanding não foi esclarecido o critério de seleção dos poetas; na de Zheng Weiming, o que prevaleceu não foi somente o de residência, mas também o de tema.

$\mathrm{Na}$ antologia organizada por Yao e Arrimar encontram-se, entre os poemas chineses, uma teia que vai desde imagens sutis de aspectos da natureza que sugerem a solidão de se viver numa cidade em meio a rostos estranhos, como em "Cidadezinha", de Wang Hao Han até a denúncia explícita dos problemas da cidade, como em "Paisagem de Macau", de Gao Ge, ou "Incinerador", de Wu Guo Chang:

Cidadezinha

Os raios solares decorando a cidadezinha no Outono

Mesmo as ruelas partilham da sombra do sol

A trepadeira verde sobe janelas desbotadas 
e as aldrabas da porta ferrugenta fecham o silêncio.

$[\ldots]$

Em todos as ruas apenas olhos estranhos

Eu deixo repousar a saudade nas acácias

e aguardo secretamente que Maio floresça rubro

[...] (Tradu. Yao Jinming, op. cit.,194)

Paisagem de Macau

[...]

O Deus que protege a Praça do Cavalo de Cobre saiu do memorial ainda numa postura de dom Quixote

e os alcoviteiros adaptaram histórias eróticas com as lendas do herói.

São histórias que se repetem todas as noites

porque nas gaiolas de luxo vive-se um ambiente sensual

em que os homens sobrevivem com uma sensação amorosa

Mas a questão é como manter a eterna erecção

e como fortalecer o regime representativo com o bálsamo mágico da Índia

"O jogo moderado dá prazer" é justificativa do público para se divertir

Os "Come-moedas" funcionam para criar efeitos publicitários

Desde os assaltos dos piratas até aos desafios contra o rei do casino

tudo é uma combinação da civilização ocidental e da sabedoria oriental.

[...] (Icem, pp. 143-144)

Incinerador

Quando chegamos frente ao sol

o fumo preto da fábrica volta a rir cinicamente

$[\ldots]$

Trabalhar um dia todo para trocar por uma noite que se consome

no êxtase das chamas de néon

E depois refrescamo-nos com uma coca-cola gelada

As correntes de lata de estanho incorporam-se delicadamente

na maré consumista

[...] (Idem, p. 226) 
Que a poesia chinesa se ponha de forma resistente aos processos de um materialismo exacerbado que tomou conta de Macau não deve causar espanto, pois é próprio da poesia resistir aos ritos do mercado, mas evocar um certo despertencimento depois da transferência do território é quase uma subversão. Seguindo os passos da leitura de Yao Jingming (inédito) da Antologia da Poesia Contemporânea de Macau, organizada por Li Guanding e publicada em 2007 como já foi referido, na poesia de Yi Ling, cidadã residente em Macau e portadora do bilhete de identidade de Hong Kong, há um questionamento acerca da própria possibilidade de Macau ser um lugar ao qual pode se pertencer. Segundo Yao, "como chinesa, não lhe custa identificar-se com a cultura chinesa mas ela não consegue identificar-se com um regime ainda menos democrático, o que lhe atribui uma postura dissidente que subsiste sob muita pressão numa sociedade conservadora como Macau”. A expressão desse incômodo, no entanto, é muito incomum. Yao considera que, muito comum, é encontrar, na poesia chinesa, antes ainda da transferência ou logo nos anos seguintes à transferência, a imagem de Macau como "um filho humilhado" por ter sido ocupada pelos portugueses. Os chineses aguardaram com confiança o futuro da região, no entanto a série de escândalos que surgiu com relação ao governo da RAEM deixou a população bastante decepcionada. Apesar disso, o constante é não intervir, como aparece no poema de Lu Aolei, traduzido por Yao da seguinte forma:

O que pensa da situação actual, por favor?

Não tenho nada a dizer.

Qual é sua opinião sobre a prevenção da epidemia, por favor?

Óptimo! Não aponte a câmara para mim.

Onde é que vamos, por favor?

Silêncio! Distribua as cartas!

Como é Macau de agora?

Chegue ao balcão 2 para apostar.

$[\cdots]$

Seja na imagem de um exílio na terra própria, da dificuldade de se enraizar, da monotonia repetida, do vazio, do tédio ou da solidão, a Antologia da Poesia Contemporânea de Macau parece vir para desconcertar o leitor, contrapondo-o aos slogans que circulam nos discursos oficiais e turísticos da cidade. 


\section{Uma nova aposta: a poesia de língua inglesa.}

O título da apresentação de Yao Jingming, no Congresso "Macau na escrita, escritas de Macau" - "Em busca do habitável" - parece reforçar a idéia de uma necessidade de os poetas de Macau pensarem o espaço vivido no cotidiano da própria cidade. Nesse sentido, talvez, fosse pertinente olhar para a um terceiro espaço linguístico da conformação das vivências urbanas - o de língua inglesa.

Devido às dificuldades que os chineses têm para aprender o português e vice-versa, que os portugueses têm para aprender o chinês, é comum, entre as comunidades, que a comunicação se dê em inglês, língua estrangeira que ambas as comunidades, com acesso à educação formalizada, dominam. Hoje, na região, devido a oportunidades várias de emprego na área de serviços, o domínio da língua inglesa, especialmente pela expansão dos cassinos, vem sendo bastante reforçado. Também as migrações de mão-de-obra especializada do sudeste asiático e da Austrália para Macau está formando uma nova comunidade de língua inglesa com estadia duradoura na região.

Num gesto bastante "novo", em 2008, Christopher Kelen e Agnes Vong publicaram uma antologia de poesia contemporânea de Macau - I roll the dice, a primeira tentativa séria de reunir a poesia de Macau para um público leitor de língua inglesa, como afirma o editor na introdução do livro. Mais da metade dos poemas da antologia (em torno de 300) foram traduzidos do chinês, perto de um quarto do português e o resto foi escrito originalmente em inglês. Entre os mais de 100 poetas que participam da antologia, 33 escreveram originalmente em inglês. Isso permite a Kit Kellen afirmar que: "[the number of untranslated poems] attests the local creation of a new English literature". Literatura inglesa ou literatura inglesa de Macau querendo dizer literatura de Macau em língua inglesa? Essas definições são muito problemáticas ainda em Macau. A literatura de Macau parece oscilar entre um esvaziamento, já que todos os poetas podem ser incluídos em outras literaturas, como a inglesa, a portuguesa ou a chinesa, e uma hiper abrangência, se todas as línguas faladas no território vierem a constituir a sua definição.

Explicamos também que a maioria dos poemas chineses e portugueses dessa antologia em língua inglesa foram recolhidos das antologias anteriormente referidas (tanto as chinesas quanto a de Yao) e que o critério de seleção 
parece bem próximo ao de Zheng Weiming - poesia "de e sobre Macau". O trabalho foi "em processo" e durou 3 anos. Incluiu em torno de 15 tradutores. A edição foi limitada para ser vendida apenas em Macau.

Muito elucidativa também são as palavras de Kit Kellen ao explicar o objetivo principal da antologia: "our aim in this case has been to create an inclusive anthology with a democratic tone; that is, to represent as many and as varied poetic voices as pratical". Se por um lado o critério de seleção dessa antologia é altamente contestável, pois para Yao Jingming este "sobre Macau" pode "não significar nada" em termos de conceituação para a definição de "literatura de Macau", por outro, sem dúvida é a mais abrangente e completa antologia de poesia contemporânea de Macau feita nos últimos tempos. Além disso, como já observamos, ela dá visibilidade às comunidades minoritárias de língua inglesa e ao mesmo tempo à língua franca utilizada em Macau.

Kit Kellen, australiano, professor da Universidade de Macau de redação criativa, poeta e editor, parece ver o espaço citadino de Macau como esse lugar de muitas possibilidades e também de determinações. Para sobreviver à intensa pluralidade de signos da cidade é necessário fazer escolhas o tempo todo. Por sobre o lance da dados mallarmeniano, é posto, no seu "poem for Macau", o rolar dos dados dos cassinos:

poem for Macao

I roll the dice

and the numbers

fall out

they spread on the table

I think I hear

a sigh of relief

now luck is everywhere

for good or for ill

everyone has it

the dice are blank

as if to say 
'now it's your turn -

Choose!' (p.123)

Próprio dos espaços urbanos híper semiotizados, o prazer estético de redescobrir e regenerar a cada vez (que os dados são lançados) a força inventiva que eles podem transmitir, existe na atenção do olhar dos poetas. Inventar modos de trazer à tona as peculiaridades dessa cultura multicultural parece ser um desafio aos poetas de Macau de todas as línguas.

\section{Cumplicidades rituais: a poesia de Fernanda Dias}

As culturas que compõem a região, apesar de serem independentes, têm seus pontos de contato. Escolho a poesia de Fernanda Dias para explorar o espaço de interculturalidade, a partir do espaço lingüístico português, no seus limites do representável, por ser nela que este se apresenta de forma mais intensa. Em outro número da Revista Atlântica e em outros lugares já referi, de modo mais geral, a poesia portuguesa que foi produzida na região, durante o período de transição. ${ }^{1}$ Nascida em Moura, no Baixo Alentejo, teve/tem uma vivência diaspórica em Macau, ao longo de 20 anos. Lá publicou os livros Horas de papel: poemas para Macau (1992), Rio de Erbu (1999) e Chá Verde (2002). Também, em Macau, publicou o livro de contos Dias da prosperidade (1998), as traduções Poemas de Uma Monografia de Macau (2004) e Poemas de Gao Ge (2007), além de traduções livres de poesia e contos chineses na Revista Cultural de Macau. Para lá da atividade literária, Fernanda Dias trabalhou na Oficina de Gravura da Academia de Artes visuais de Macau, com Bartolomeu dos Santos. Entre as exposições de que participou, destacam-se "Imitação dos Muros"(2002) e "Rosas de Shangrila" (2005).

Com essa formação, não é incomum a percepção crítica tanto dos elementos visuais quanto orientais na sua obra poética. De alguma forma, a expressividade da poética de Fernanda Dias parece recuperar, mas não de uma maneira estilizada, aquela definição de arte antiga, chinesa: caligrafia, poesia e pintura como uma mesma arte, investida de uma troca harmoniosa entre

1 Ver SIMAS, Monica. Margens do destino: Macau e a literatura em língua portuguesa. São Caetano do Sul: editora Yendis, 2007. 
as potencialidades celestes e as manifestações terrestres. E não é simples casualidade que dois dos seus livros de poesia, Chá verde e Rio de Erhu, tenham prefácios de chineses, o primeiro de Yao Jingming e o segundo de Lee Shuk Yee. No prefácio de Chá verde (2002), Yao Jingming afirma:

Há um enorme mundo que cabe nesta cidade pequena. Na poesia de Fernanda assistimos também a seu vôo sobre a cidade. Pela fenda de cimento, a poetisa voa para fora. Voa como libélula. Nas suas asas compridas, o espaço perdeu a fronteira: o Oriente e o Ocidente fazem-se num mundo único, onde ela sobrevoa os lagos de Nam Van antes do pôr do sol alentejano. (p.7)

Um livro assim, só o escreve quem tem intimidade com o chá, digo, o ritual absorvido no dia a dia, que acompanha o bem e o mal desses dias, dentro de um mundo intimista cuja aliança com o outro é buscada palavra a palavra.

\section{definição}

chá: esse outro meu coração verde

que fora do meu peito pulsa.

ritual de silêncio, amargo e quente, que te dou a beber em cada taça.

Seja nos "ritos do fim do dia" (p.39) seja na permanência do inefável, o aroma do chá, ou no olhar que fica fitando a cidade mesmo depois de partir, temos uma poesia cujos sentidos desdobram-se em errâncias que vão realizando uma espécie de intersemiose.

amo la dor

Veng Kei, amo la dor

escreveu o calígrafo, na vertical

na chapa verde e ondulada

e o mesmo em chinês por baixo

amo la dor, cutelos e tesouras, que grito rouco, vermelho espesso, escrito em três traços! 
sólido nó ocasional, amarra duas escritas. (p. 45)

Numa cidade em que não são raros os enganos lingüísticos, nas traduções e na comunicação dos dias, as errâncias poéticas de Fernanda Dias constróem uma sensibilidade convergente em que eles são a pura força da vontade de se "ser com".

No prefácio de Rio de Erhu (1999), Lee Shuk Yee disserta sobre o escoamento da multiplicidade de formas (o rio) que encontra no livro, por onde perpassam os acordes vibrando com as sonoridades dos 5 elementos presentes no pensamento chinês: metal, madeira, água, fogo e terra (Cf. pp. 3-5).

A expressividade poética em língua portuguesa que Fernanda Dias cria é o mais inovador de Macau em termos de interculturalidade. Porque Rio de erhu (1999) só poderia ser nascido de um verdadeiro encontro com a China.

rio de erhu

porque me deste vida,

uma outra vida, que não a vida que eu pensava

que era única,

e quebraste a dura noz da rotina

para dela saírem pássaros de fogo

voando céleres para o céu,

para a pura luz,

e todas as pétalas de uma primavera

nunca pressentidada

caindo sobre a hora-agora

como sobre a rotundidade de um fruto,

o perfil de uma pequena ilha,

o brilho de uma gota de puro pranto,

e puro gozo

$[\ldots]$

A “outra vida" ensolarada que este "eu” lírico incorpora está relacionado a um "tu” polissêmico, o erhu - o violino chinês -, que cumpre o espaço amante, do amado lugar em que se vive, da poesia também. Surge na alquimia dos 
sentidos, das vibrações do movimento fecundador, uma nova sementeira, "a rotundidade de um fruto", "o perfil de uma pequena ilha", a potencialidade circular da criação. A ciência da fecundação traz um êxtase, expresso naquele "brilho de uma gota de puro pranto/ de puro gozo."

Macau é o topônimo da "rotina diária" do livro, visualizado "no pátio do Colégio Yuet Wa" ou "na piscina do Tap-Siac", do poema dia lento (p.47); na Rua da Palha, do poema "o olho", ou nos poemas intitulados "porto interior"(p. 33), ou "coloane" (p. 75), ou ainda naquela "geografia estrita dos [meus] dias", que inclui uma torre entre um farol e um braço de rio, do poema "biografia" (p. 48). O sujeito poético encontra ali, em Macau, além da exterioridade concreta do espaço, a porta maravilhosa para uma exultante convivência, ainda que, como todas as impossíveis definições, seja esta experiência paradoxal, feita de "alegres ácidos momentos" (p.49).

Dividido em quatro partes - "Rio de erhu", "Invenção do amante", "Interior com poetas" e "Contos da bruma e do vento" - os versos trazem as ressonâncias da natureza, especialmente das plantas, a luz em cada uma das suas cores, a disposição das coisas, exterior e interior, o outro sempre, nomeado, na maioria das vezes, através de uma sensorialidade erótica.

Sigo mais um pouco o poema "rio de erhu" - "recebi o dom de ouvir/ por todos os poros da minha pele/ em silêncio cantando/ como uma mãe recém-fecundada" (p. 6) O "tu" fecundador, o som que "desliza,/ cai, flutua, voa" transforma-se em novo canto, por um “eu” que é receptáculo da força criativa, formando um corpo poético híbrido novo.

Já em Horas de papel (1992), Macau é o espaço eleito para se questionar a legibilidade do mundo, as permanências e as transformações da comunicação. Neste primeiro livro de poesia da autora, aproveitando-se do desfazimento de estruturas (penso nas transformações radicais por que passou a estrutura urbana de Macau entre 1987 e 1999), o sujeito lírico elabora "sobras" para produzir sentidos contra os "lugares comuns" que adjetivam o espaço - "Macau também é isto: / ocasionais palavras amarelas/ escritas com crisântemos desfeitos" (p. 15). Ângulos inusitados aparecem no desenho criado da cidade. No itinerário da memória, cabem as damas de Li Bai ou o unicórnio de Tu $\mathrm{Fu}$, entre as coisas simples do cotidiano e daquilo que se tem hoje e amanhã não - "Amanhã, meu rosa-ocre destas águas?" / meu livro de Mishima, minha luz cor-de-chá?/ Minha cabaia-chacha com debrum de anil?” (p. 39). 
Uma dose de maravilhamento e de revolta caracterizam o gesto inicial da escrita poética de Fernanda Dias, promovendo um avançar de frente do sujeito lírico a opacidade do mundo. Enfrentar a cegueira do hábito constituído, das ideologias que atravessam as histórias, dos orientalismos que se repetiram nos repertórios da literatura de expressão portuguesa, a ideia de que "a terra é semelhante e pequenina/ e ha uma maneira de viver" parece ser o grande desafio a que essa poesia se lançou com muita força e propriedade. E será de fato original no fluxo de diferenças, entre espaços pouco compartilhados de Macau.

\section{Referências Bibliográficas}

ARRIMAR, Jorge e YAO Jingming, sel. e org. Antologia de Poetas de Macau. Macau: Instituto Camões, Instituto Cultural de Macau e Instituto Português do Oriente, 1999. BERARDINELLI, Cleonice. Poemas de Álvaro de Campos. Lisboa: ICM, 1990.

DIAS, Fernanda. Chá verde. Macau: CACultura, 2002. . Rio de Erbu. Macau: FAB, 1999. . Horas de papel (poemas para Macau). Macau: IPOR, 1992. . Tradução: Gao Ge: poemas. Macau: Instituto Português do Oriente, 2008. . Tradução: Poemas de Uma Monografia de Macau: Colecção Pavilhão Insólito, COD, 2004.

KELEN, Christopher (Kit) Kelen e VONG, Agnes. I roll the dice: contemporary Macao poetry. Macao: ASM, Association of Stories in Macao, 2008.

LABORINHO, Ana Paula. Prefácio. In: ARRIMAR, Jorge e YAO Jingming, sel. e org. Antologia de Poetas de Macau. Macau: Instituto Camões, Instituto Cultural de Macau e Instituto Português do Oriente, 1999.

MIU BING, Cheng Christina. Macau: a Cultural Janus. Hong Kong: Hong Kong University Press, 1999.

SIMAS, Monica. Margens do destino: Macau e a literatura em lingua portuguesa. São Caetano do Sul: editora Yendis, 2007.

YAO Jingming. "Em busca do habitável: a partir da Antologia de Poesia Contemporânea de Macau", (inédito) artigo apresentado no encontro "Macau na escrita, escritas de Macau", na Universidade de Lisboa, em outubro de 2007.

2 Do poema "Opiário", de Álvaro de Campos. In: BERARDINELLI, Cleonice. Poemas de Álvaro de Campos. Lisboa: ICM, 1990, p.54. 